\title{
La baja utilidad de la determinación del ADN del VPH en la región distal de la uretra masculina
}

\author{
Ahideé $G$ Leyva-López, $M$ en $C$, ${ }^{(1)}$ Carlos E Aranda-Flores, MC, ${ }^{(2)}$ \\ Carlos Conde-G onzález, D r en C, ${ }^{(3)}$ Eduardo C Lazcano-Ponce, Dr en C. ${ }^{(1)}$
}

\section{LeyvaLópez AG,ArandaFlores CE, Conde-González C, Lazcano-Ponce EC. La baja utilidad de la determinación del ADN del VPH en la región distal de la uretra masculina. Salud Publica Mex 2003;45 supl 5:S589-S593. El texto completo en inglés de este artículo está disponible en: http://www.insp.mx/salud/index.html}

\section{Resumen}

Objetivo. Determinar la prevalencia uretral del ácido desoxirribonucleico del virus de papiloma humano, condilomatosis clínica y subclínica, en hombres cuyas parejas sexuales tuvieron el antecedente de neoplasia intraepitelial cervical. Material y métodos D e octubre de 1997 a ago sto de 1998 se hizo un estudio transversal; se incluyeron 200 hombres de entre 17 a 64 años de edad, referidos a la Coordinación de O ncología del Instituto $\mathrm{N}$ acional de Perinatología, de la Ciudad de México, porque sus parejas regulares sexuales tuvieron el antecedente de neo plasia intraepitelial cervical. Se llevó a cabo un examen físico del pene (penoscopía) con la aplicación de ácido acético a 3-5\%, y con el uso de un colposcopio se localizaron y evaluaron zonas acetoblancas y cambios vasculares, interpretados como anormales, asociados con la infección por el virus del papiloma humano. La determinación del ADN deVPH se verificó por PCR e hibridación en línea reversa. El análisis estadístico exploratorio y univariante se realizó con el paquete Stata V6.0. Resultados En las 200 muestras recolectadas de células exfoliadas de la uretra el gen de $\beta$-globina estuvo presente en $93.5 \%$ (187/200), y el ácido desoxirribonucleico del virus del papiloma humano fue

\author{
Leyva-López AG,Aranda-Flores CE, \\ Conde-González C, Lazcano-Ponce EC. \\ Low usefulness of HPV DNA determination \\ in the distal region of the male urethra. \\ Salud Publica Mex 2003;45 suppl 5:S589-S593. \\ The English version of this paper \\ is available at: http://www.insp. mx/salud/index.html
}

\begin{abstract}
A bstract
Objective.To assess the prevalence of Human Papillomavirus (HPV) Deoxyribonucleic acid (DNA), and of clinical and subclinical condilomatosis in men whose sex partners had been diagnosed with cervical intraepithelial neoplasia. Material and MethodsA cross-sectional study was conducted from 0 cto ber 1997 to August 1998, among 200 men aged 17 to 64 years referred to the 0 ncology Department of the $\mathrm{N}$ ational Institute of Perinatology in Mexico City. A physical examination of the penis (penoscopy) was performed after applying 3-5\% acetic acid. A colposcope was used to identify acetowhite areas and vascular abnormalities associated with HPV infection. HPV DNA was detected by PCR and reverse line hybridization. The exploratory and univariant statistical analysis was made with the package StataV6.0. Results. The $\beta$-glo bin gene was present in $93.5 \%$ $(n=187)$ of the 200 urethral exfoliated cell samples collected. HPV DNA was detected in only $2 \%$ (4/187) of the study subjects. Penoscopy data showed the presence of acetow hite areas in 43\% (81/187) of subjects. Conclusions Study findings show that the presence of HPV DN A in urethra is uncommon, as has been reported in several previous
\end{abstract}

Este estudio fue realizado gracias al apoyo del Instituto N acional de Perinatología, sito en México, DF y del Instituto N acional de Salud Pública de México, en Cuernavaca, Morelos.A simismo, al del Consejo N acional de Ciencia y Tecnología y de Roche Molecular Systems Inc., de Alameda, CA, Estados U nidos de A mérica.

(1) Centro de Investigación en Salud Poblacional. Instituto Nacional de Salud Pública. Cuernavaca, Morelos, México.

(2) Coordinación de 0 ncología, Instituto Nacional de Perinatología. México, D F, México.

(3) Centro de Investigación sobre Enfermedades Infecciosas. Instituto N acional de Salud Pública. Cuernavaca, Morelos, México.

Fecha de recibido: 11 de julio de 2001 - Fecha de aprobado: 6 de noviembre de 2002

Solicitud de sobretiros: M en C. A hideé G Leyva-López. Centro de Investigación en Salud Poblacional. Instituto N acional de Salud Pública. Avenida Universidad N 0.655, Colonia Santa María A huacatitlán 62508 Cuernavaca, Morelos, México.

Correo electrónico: leyvalop@.insp.mx 
detectable solamente en $2 \%$ (4/187) de los sujetos. Por medio de la penoscopía se observó la presencia de zonas acetoblancas en 43\% (81/187) de los sujetos. Conclusiones En este estudio se observa que la presencia del ácido desoxirribonucleico del virus del papiloma humano en la uretra masculina es poco común, como lo reportan estudios internacionales. Es necesario realizar investigaciones que evalúen esta presencia en glande y surco balano prepucial, en comparación con la región distal de la uretra. El texto completo en inglés de este artículo está disponible en: http:// ww w.insp.mx/salud/index.html

Palabras clave: papilomavirus humano; reacción en cadena de la polimerasa; hombres; uretra; México studies. Research is needed to evaluate the presence of HPV DNA in the coronal sulcus, as compared with the distal urethral region.The English version of this paper is available at: http://www.insp.mx/salud/index.html

Key words: papillomavirus, human; polymerase chain reaction; men; urethra; Mexico a infección por el virus del papiloma humano (VPH) es considerada actualmente una causa necesaria para el desarrollo de cáncer cervical $(\mathrm{CaCu}){ }^{1}$ Nuevas alternativas de detección y tratamiento de esta infección constituyen las principales líneas de investigación para la prevención primaria y secundaria de $\mathrm{CaCu}$.

Sin embargo, a pesar de que la historia natural del VPH genital en hombres es de potencial importancia para establecer estrategias que pudieran disminuir el reservorio del virus ${ }^{2}$ que disemina la infección, escasa es la información al respecto. ${ }^{3,4}$ La infección en hombres tiene la peculiaridad de no producir síntomas y, en éstos, en la mayoría de las veces no existen lesiones visibles. ${ }^{5}$ Varios métodos han sido usados para detectar en ellos el VPH, incluyendo examen clínico, citología uretral, penoscopía, histología, pero las únicas pruebas que han tenido la capacidad para identificar diversos genotipos de VPH son las de hibridación molecular. ${ }^{6}$ Además, no existe un método definitivo para la colección del espécimen en hombres. Algunos métodos incluyen el uso de diferentes instrumentos, tal es el caso del cepillo, con el cual se obtienen células exfoliadas de la uretra en escasa cantidad, y muchos de los estudios se han hecho con bajas tasas de respuesta. $^{3}$

Reportes previos han encontrado una baja prevalencia del ácido desoxirribonucleico (AND) del VPH uretral, tanto en individuos con condilomas clínicos externos, como sin lesiones. ${ }^{5,7}$

El presente estudio tuvo como objetivo determinar la prevalencia del ADN del VPH uretral, de condilomatosis clínica y subclínica en hombres residentes en la Ciudad de México, cuyas parejas regulares sexuales tuvieron el antecedente de neoplasia intraepitelial cervical (NIC).

\section{Material y métodos}

Durante el periodo de octubre de 1997 a agosto de 1998 se hizo un diseño de estudio tipo transversal; se incluyeron 200 hombres de entre 17 a 64 años de edad, quienes acudieron a practicarse un examen físico del pene (penoscopía), en la Coordinación de Oncología del Instituto Nacional de Perinatología (INPer) de la Ciudad de México.

Los sujetos elegibles fueron hombres cuyas parejas sexuales tuvieron el antecedente de NIC (evaluadas por medio de citología, colposcopía y biopsias dirigidas) con buen estado de salud física y mental; previa invitación, aceptaron formar parte del estudio, firmando una carta de consentimiento informado.

\section{Recolección de datos y de muestras biológicas}

Dos entrevistadores estandarizados aplicaron un cuestionario validado con dos pruebas piloto. El cuestionario incluyó preguntas a cada participante como lugar de nacimiento, edad, escolaridad, estado civil, hábito tabáquico y comportamiento sexual (parejas regulares y ocasionales, trabajadoras del sexo comercial, tipo de actividad sexual -sexo anal, oral y homosexual-, uso de condón y circuncisión).

Se recolectaron muestras de células exfoliadas de la uretra para la detección del ADN del VPH. Para ello, se les indicó a los participantes no orinar por lo menos una hora antes de dicha recolección. La toma del espécimen biológico se realizó con ayuda de un hisopo Acellon Multi bio-muestras (Medscand AB, FL, Estados Unidos de América (EUA)). El instrumento estéril se insertó suavemente $2 \mathrm{~cm}$ en la uretra, se giró a 360 grados y se retiró lentamente. Las células recolectadas 
se suspendieron en un tubo cónico con tapón de rosca que contenía $20 \mathrm{ml}$ de una solución salina de fosfatos. Las muestras recolectadas fueron transportadas, bajo refrigeración, al laboratorio del Instituto Nacional de Salud Pública (INSP), en donde fueron almacenadas a $-70{ }^{\circ} \mathrm{C}$, y posteriormente procesadas.

\section{A nálisis de muestras biológicas}

\section{Determinación del ADN del VPH}

La determinación del ADN del VPH fue hecha por personal del Instituto Nacional de Salud Pública (INSP), capacitado en el Departamento de Microbiología e Inmunología Molecular de la Universidad de Johns Hopkins, (Baltimore, EUA).

El VPH se determinó por el método de la reacción en cadena de la polimerasa (PCR, por sus siglas en inglés). La calidad de la muestra se evaluó coamplificando un fragmento de gen de $\beta$-globina. Para la tipificación del VPH, los productos de PCR, se hibridaron en tirillas con sondas inmovilizadas. ${ }^{8}$

Examen físico del pene (penoscopía)

La penoscopía fue realizada por un médico adscrito al servicio. Para ello se aplicó una solución de ácido acético a 3-5\% en el meato uretral, el glande, el prepucio, el surco balano-prepucial y el escroto. Después de tres minutos, con un colposcopio, ${ }^{2,9}$ se localizaron y evaluaron zonas acetoblancas y cambios vasculares, interpretados como anormales, que en reportes previos han sido denominados condiloma aplanado, papular o acuminado..$^{2,9,10}$

\section{Metodología estadística}

La información se capturó en FoxPro V2.6 (Redmond WA). El paquete estadístico STATA V6.0 ${ }^{11}$ se utilizó para el análisis univariado de todas las variables. Estas se midieron sobre una escala continua y exploradas en términos de su distribución original, y también en categorías. Se construyó un índice de nivel socioeconómico (NSE), ${ }^{12}$ con tres categorías, por medio de cinco variables (número de personas que vivían en la casa, número de cuartos, disponibilidad de agua potable, condiciones sanitarias y educación).

\section{Resultados}

\section{Características de la población}

Un total de 200 hombres participaron en el estudio, con una media de edad de 33.3 años (intervalo=17-64).
Se excluyeron del estudio a 13 sujetos (quienes presentaron $\beta$-globina negativa). De los 187 restantes, $68 \%$ (128/187) estaban casados, 86\% (160/187) tenían algún trabajo a sueldo en el momento de ser entrevistados, 33\% (61/187) pertenecían al NSE alto, 28\% (54/187) al medio, y 39\% (72/187) al bajo.

Respecto al comportamiento sexual, 76\% (143/187) habían iniciado relaciones sexuales antes de los 20 años de edad; la mayor parte de los sujetos reportaron ser heterosexuales, 97\% (182/187) y 3\% (5/187) eran bisexuales. De acuerdo con el número de parejas 93.5\% (175/187) respondieron haber tenido entre 1 a 4 parejas sexuales regulares en toda su vida; $30 \%$ (56/187) de los sujetos tuvieron historia con parejas ocasionales, y 70\% (132/187) reportaron haber tenido relaciones sexuales con trabajadoras del sexo comercial; $34 \%$ (64/187) usaban el condón durante sus relaciones sexuales, y por último, 18\% (34/187) estaban circuncidados.

\section{Detección de ß-globina y ADN del VPH}

Las secuencias de $\beta$-globina fueron detectadas en $93.5 \%$ (187/200) de las muestras. El 6.5\% (13/200) sujetos que presentaron $\beta$-globina negativa se excluyeron del estudio. El ADN del VPH fue detectable solamente en $2 \%$ $(4 / 187)$ de las muestras que fueron $\beta$-globina positiva.

Los cuatro sujetos positivos al ADN del VPH presentaron los tipos de VPH de alto riesgo: 16 (2/4), $56(1 / 4)$, y $59(1 / 4)$.

\section{Penoscopía}

Con la penoscopía, 43\% (81/187) de los sujetos mostraron lesiones genitales externas. De los 81 sujetos, en 97.5\% (79/81) las zonas acetoblancas fueron clínicamente clasificables como condiloma plano o papular. El 2.4\% (2/81) presentó lesiones por condiloma acuminado; ambos casos se localizaron en el escroto. El condiloma plano y el papular se encontraron en el cuerpo del pene en $62 \%$ (50/81), 22\% (18/81) en el prepucio, $10 \%(8 / 81)$ en el glande, $5 \%(4 / 81)$ en el meato uretral y $5 \%(4 / 81)$ en el frenillo (cuadro I).

\section{Discusión}

Desde que el genoma del VPH fue activado y transcrito en células, las proteínas específicas virales y las técnicas inmunológicas se constituyeron en una clara alternativa diagnóstica; principalmente porque se encontró evidencia de que las proteínas E6 y E7 participan en la promoción de lesiones premalignas del cérvix. ${ }^{13}$ Las limitaciones de los métodos utilizados están relacionadas con su sensibilidad, utilidad clínica, complejidad, 


\section{Cuadro I \\ Examen físico (penoscopía). Prevalencia y LOCALIZACIÓN DE LA LESIÓN ANOGENITAL EN HOMBRES, Ciudad de MÉxico, 1997-1998}

\begin{tabular}{|c|c|c|c|c|c|c|c|c|}
\hline \multirow{3}{*}{ Localización } & \multirow{2}{*}{\multicolumn{2}{|c|}{ Casos }} & \multicolumn{6}{|c|}{ Condiloma } \\
\hline & & & \multicolumn{2}{|c|}{ Plano } & \multicolumn{2}{|c|}{ Papular } & \multicolumn{2}{|c|}{ Acuminado } \\
\hline & $\mathrm{N}$ & $\%$ & $\mathrm{~N}$ & $\%$ & $\mathrm{~N}$ & $\%$ & $\mathrm{~N}$ & $\%$ \\
\hline Prepucio & 18 & 20.9 & 13 & 15.1 & 5 & 5.8 & 0 & 0 \\
\hline Glande & 8 & 9.3 & 5 & 5.8 & 3 & 3.5 & 0 & 0 \\
\hline \multicolumn{9}{|l|}{ Región distal } \\
\hline de la uretra & 4 & 4.7 & 4 & 4.7 & 0 & 0 & 0 & 0 \\
\hline Cuerpo del pene & 50 & 58.1 & 35 & 40.7 & 15 & 17.4 & 0 & 0 \\
\hline Escroto & 2 & 2.3 & 0 & 0 & 0 & 0 & 2 & 2.3 \\
\hline Frenillo & 4 & 4.7 & 4 & 4.7 & 0 & 0 & 0 & 0 \\
\hline Total & $86^{*}$ & 100 & 61 & 71.0 & 23 & 26.7 & 2 & 2.3 \\
\hline
\end{tabular}

* Incluye cinco casos con condiloma en más de un solo lugar

reproducibilidad, facilidad de manejo y disponibilidad comercial. ${ }^{6,10}$

En hombres, las diferencias en los métodos de colección del espécimen (células exfoliadas de la uretra, el instrumento usado para dicha colección, la composición del medio de transporte) influyen grandemente en la reproducibilidad y la sensibilidad analítica del diagnóstico del VPH. 2,6,7 Diversos estudios han tratado de evaluar, sin mucho éxito, la factibilidad de utilizar muestras de orina y de pene/uretra para detectar la presencia del ADN del VPH (cuadro II).

En nuestro estudio se determinó la prevalencia del ADN del VPH uretral en hombres por PCR. Aunque las secuencias de $\beta$-globina fueron detectadas en 93.5\% de las muestras (garantizando la calidad de las muestras recolectadas), el ADN del VPH uretral fue detectable solamente en $2 \%$. De acuerdo con Melchers y colaboradores, ${ }^{10}$ en un estudio aplicado en 17 hombres con condiloma acuminado en el meato uretral, referidos a la Clínica de Enfermedades de Transmisión Sexual (ETS) del Hospital Académico Rotterdam, se analizó la presencia del ADN del VPH en muestras de orina, y se reportó una prevalencia de $88 \%$; otro estudio, hecho por Lazcano y colaboradores ${ }^{14}$ en 120 hombres asintomáticos, en México, analizó la presencia del ADN del VPH en muestras de orina y de surco balano-prepucial encontrando una prevalencia del ADN del VPH de $11.8 \%$ y $42.7 \%$, respectivamente, demostrando con ello que la presencia del ADN del VPH uretral se encuentra en aquellos sujetos con condilomas clínicos intrauretrales. ${ }^{2}$

Respecto de la penoscopía, Barraso y colaboradores $^{2}$ reportaron una prevalencia de $64.4 \%$ de lesiones asociadas con la infección del VPH. En este estudio, al realizarse la penoscopía, se encontró una alta prevalencia (43\%) de zonas acetoblancas clínica y colposcópicamente detectables, probablemente asociadas a esta infección. Las zonas acetoblancas en su mayor parte se localizaron en el cuerpo del pene, y en una menor proporción en el meato uretral. Rothman y cola-

\section{Cuadro II \\ Estudios ReALIZAdos PARA DETECTAR VIRUS DE PAPILOMA HUMANO EN HOMBRES}

\begin{tabular}{|c|c|c|c|c|c|c|}
\hline Estudio & $\begin{array}{l}\text { Población de } \\
\text { estudio }\end{array}$ & $\begin{array}{l}\text { Tamaño } \\
\text { muestral }\end{array}$ & $\begin{array}{l}\text { Muestras } \\
\text { de orina }\end{array}$ & $\begin{array}{l}\text { Muestras de } \\
\text { pene/uretra }\end{array}$ & $\begin{array}{c}\text { Resultados } \\
\text { VPH + en orina }\end{array}$ & VPH + Pene/uretra \\
\hline $\begin{array}{l}\text { Holanda, Melchers } \\
\text { y colaboradores }{ }^{10} 1989\end{array}$ & $\begin{array}{l}\text { Hombres con condiloma } \\
\text { en el meato uretral }\end{array}$ & $\begin{array}{c}31 \\
17 \text { casos/14 controles }\end{array}$ & 17 & 0 & $\begin{array}{c}\text { Casos }=15(88 \%) \\
\text { Controles }=0\end{array}$ & No se obtuvo \\
\hline $\begin{array}{l}\text { Londres, Hillman y } \\
\text { colaboradores } 1993\end{array}$ & $\begin{array}{l}\text { Hombres con } \\
\text { dermatosis genital }\end{array}$ & 100 & 59 & 100 & $6(10 \%)$ & $21 / 85(25 \%)$ \\
\hline $\begin{array}{l}\text { Londres, Hillman y } \\
\text { colaboradores }{ }^{16} 1993\end{array}$ & $\begin{array}{l}\text { Hombres parejas de } \\
\text { mujeres con neoplasia cervical }\end{array}$ & 116 & 15 & 116 & $1(6.3 \%)$ & $22(19 \%)$ \\
\hline $\begin{array}{l}\text { Malmö, Forslund y } \\
\text { colaboradores }^{17} 1993\end{array}$ & Militares & 138 & 138 & 138 & $8(5 \%)$ & $12(8 \%)$ \\
\hline $\begin{array}{l}\text { Udine,Astori y } \\
\text { colaboradores }{ }^{18} 1995\end{array}$ & $\begin{array}{l}\text { Hombres asintomáticos } \\
\text { parejas de mujeres con } \\
\text { VPH positivo }\end{array}$ & 70 & 70 & 70 & $\begin{array}{c}\text { PCR: } 18(33 \%) \\
\text { Dot blot: } 12(27 \%)\end{array}$ & $\begin{array}{c}62(89 \%) \text { de las } \\
\text { muestras fueron } \\
\text { inadecuadas }\end{array}$ \\
\hline $\begin{array}{l}\text { México Lazcano y } \\
\text { colaboradores }^{14} 2001\end{array}$ & $\begin{array}{l}\text { Trabajadores /estudiantes } \\
\text { Morelos, México }\end{array}$ & 120 & 120 & 120 & $2(11.8 \%)$ & $41(42.7 \%)$ \\
\hline
\end{tabular}


boradores $^{7}$ efectuaron un estudio en la clínica de ETS del Centro Médico, Seattle, EUA, en 90 hombres con condiloma en el meato externo, y reportaron que los condilomas intrauretrales son poco comunes. En este estudio se encontró un mayor número de características clínicas posiblemente asociadas a la infección por el VPH en aquellos hombres que no utilizaban condón, y en quienes reportaron un mayor número de parejas sexuales (ocasionales y trabajadoras del sexo comercial). Conviene destacar que estos resultados no fueron diagnosticados histológicamente. La alta prevalencia encontrada también pudiera deberse a distintas causas, como candidiasis, foliculitis, soriasis y otras reacciones alérgicas. ${ }^{2}$

Finalmente, en este estudio la presencia del ADN del VPH en la región distal de la uretra fue baja. Por esta razón futuros estudios de la historia natural de la infección por el VPH deben cuestionar seriamente la utilidad de obtener muestras de dicha región. Asimismo, se considera que tomar muestras del surco-balano prepucial y del glande para obtención de células exfoliadas de pene puede ser la mejor alternativa para tipificar y documentar la infección por el $\mathrm{VPH}^{6,14}$ ya que el no obtener muestras de uretra puede condicionar el aumento de altas tasas de respuesta cuando se planifiquen y operacionalicen estudios del VPH en hombres.

\section{Referencias}

1.W alboomers JMM, Jacobs MV, Manos MM, Bosch FX, Kummer JA, Shah $\mathrm{K}$ et al. Human papillomavirus is a necessary cause of invasive cervical cancer worldwide.J Pathol 1999;189:12-19.

2. Barraso R, Brux J, Croissant 0, 0 rth G. High prevalence of papillomavirus associated penile intraepithelial neoplasia in sexual partners of women with cervical intraepithelial neoplasia. N Engl J Med 1987;317:916-923

3. C astellsägue $X$, Muñoz N , Bosch FX. Prevalence of penile human papillomavirus DNA in husbands of women with and without cervical neoplasy: Study in Spain and Colombia.J Infect D is 1997;176:353-361.
4. Koustsky LA, Galloway DA, Holmes KK. Epidemiology of genital human papillomaviruses infection. Epidemiol Rev 1988;10:122-155. 5. Krebs HB, Helmkamp FB.Treatment failure of genital condylomata acuminata in women: Role of male sexual partner. A m J O bstet Gynecol 1991;165:337-340.

6. Muñoz N , Bosch FX, Jensen O M. Human papillomavirus and cervical cancer. Lyon, France: International A gency for Research on C ancer, Scientific Publication 1989;94.

7. Rothman I, Berger RE, Kiviat N , N avarro AL, Remington ML. U rethral meatal warts in men: Results of uretroscopy and biopsy. J U rol 1994;151:875-877.

8. G ravitt PE, Peyt CL,Apple RJ,W heeler CM. G enotyping of 27 human papillomavirus types using $L 1$ consensus PCR products by a single hibridization, reverse line blot detection method.J Clin Microbiol 1998:36:3020-3027.

9. Melchers W JG, Shift R, Stolz J, Lindeman J, Q uint GV. Human papillomavirus detection in urine samples from male patients by the polymerase chain reaction. J Clin Microbiol 1989;27:1711-1714. 10. Pinto PA, Mellinger BC. HPV in the male patient. U rol C lin N orth Am 1999;26:797-807.

11. Stata for W indows. Stata Reference Manual: Release 3.1. Sexta Edición.College Station (TX): Stata Corporation, 1993.

12. Bronfman M, G uiscafré $H, C$ astro R, Gutiérrez G. Medición de la desigualdad: una estrategia metodológica, análisis de las características socioeconómicas de la muestra. Arch Invest Med 1988;19:351-360. 13. Elbel M, Carl S, Spaderna S, Iftner T.A comparative analysis of the interactions of the $\mathrm{E} 6$ proteins from cutaneous and genital papillomaviruses with p53 and E6AP in correlation to their transforming potential. Virology 1997;239:132-149.

14. Lazcano E, Herrero R, Muñoz N , Hernández M, Salmerón J, Leyva A et al. High prevalence of human papillomavirus infection in Mexican males. Comparative study of penile-uretral swabs and urine samples. Sex Transm D is 2001;28:277-280

15. Hillman RJ, Botcherby M, Ryait BK, Hanna N, Taylor RD. D etection of human papillomavirus DNA in the urogenital tracts of men with anogenital warts. Sex Transm D is 1993;20:21-27.

16. Hillman RJ, Ryait BK, Botcherby M, W alker MN , Taylor RD. Human papillomavirus DNA in the urogenital tracts of men with genital dermatoses: Evidence for multifocal infection. Int I STD AID S 1993:4:147-154.

17. Forslund $\mathrm{O}, \mathrm{G}$ oran B, Rymark P, Bjerre B. Human papillomavirus DNA in urine samples compared with that in simultaneously collected urethra and cervix samples. J Clin Microbiol 1993;31:1975-1979. 18. Astori G, Pipan C, Muffato G, Botta GA. D etection of H PV-D N A in semen, urine, and urethral samples by dot blot and PCR. N ew Microbiol 1995:18:143-149. 